\title{
A New Extremely Halophilic, Calcium-Independent and Surfactant- Resistant Alpha-Amylase from Alkalibacterium sp. SL3
}

\author{
Guozeng Wang ${ }^{1,2 *}$, Meng Luo ${ }^{1}$, Juan Lin $^{1}$, Yun Lin ${ }^{1}$, Renxiang Yan ${ }^{1}$, Wolfgang R. Streit ${ }^{2}$, and Xiuyun Ye ${ }^{1,3}$ \\ ${ }^{1}$ College of Biological Science and Engineering, Fuzhou University, Fuzhou 350116, P. R. China \\ ${ }^{2}$ Department of Microbiology and Biotechnology, Biocenter Klein Flottbek, University of Hamburg, Hamburg 22609, Germany \\ ${ }^{3}$ Fujian Key Laboratory of Marine Enzyme Engineering, Fuzhou University, Fuzhou 350116, P. R. China
}

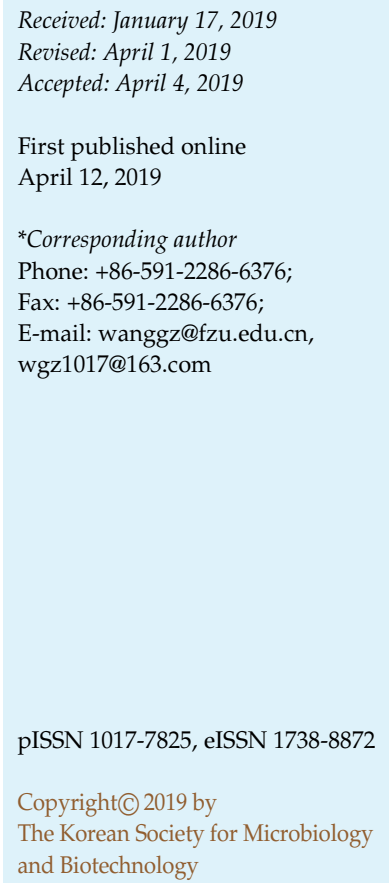

A new $\alpha$-amylase-encoding gene (amySL3) of glycoside hydrolase (GH) family 13 was identified in soda lake isolate Alkalibacterium sp. SL3. The deduced AmySL3 shares high identities (82-98\%) with putative $\alpha$-amylases from the genus Alkalibacterium, but has low identities $(<53 \%)$ with functionally characterized counterparts. amySL3 was successfully expressed in Escherichia coli, and the recombinant enzyme (rAmySL3) was purified to electrophoretic homogeneity. The optimal temperature and $\mathrm{pH}$ of the activity of the purified rAmySL3 were determined to be $45^{\circ} \mathrm{C}$ and $\mathrm{pH} 7.5$, respectively. rAmySL3 was found to be extremely halophilic, showing maximal enzyme activity at a nearly saturated concentration of $\mathrm{NaCl}$. Its thermostability was greatly enhanced in the presence of $4 \mathrm{M} \mathrm{NaCl}$, and it was highly stable in $5 \mathrm{M} \mathrm{NaCl}$. Moreover, the enzyme did not require calcium ions for activity, and was strongly resistant to a range of surfactants and hydrophobic organic solvents. The major hydrolysis products of rAmySL3 from soluble starch were maltobiose and maltotriose. The high ratio of acidic amino acids and highly negative electrostatic potential surface might account for the halophilic nature of AmySL3. The extremely halophilic, calcium-independent, and surfactant-resistant properties make AmySL3 a promising candidate enzyme for both basic research and industrial applications.

Keywords: $\alpha$-Amylase, glycoside hydrolase family 13, halophilic, surfactant-resistant, calciumindependent, Alkalibacterium

\section{Introduction}

Starch is composed of linear amylose and branched amylopectin, in which glucose units linked by $\alpha-1,4$ and $\alpha-1,6$ glucosidic bonds form the main and branched chains, respectively [1]. Usually, four types of enzymes, endoamylase, exo-amylase, debranching enzyme, and transferase, are involved in the conversion of starch [2]. $\alpha$-Amylase (E.C. 3.2.1.1) is a well-known endo-amylase that randomly catalyzes the hydrolysis of the internal $\alpha$-1,4-glucosidic bonds in starch and related carbohydrates to produce glucose, oligosaccharides, and dextrins [3]. Based on sequence similarities of the catalytic domain, $\alpha$-amylases have been classified into several glycosyl hydrolase (GH) families (http:/ / www.cazy.org/fam/acc_GH.html): 13, 57,
119 , and 126 [4]. The majority of $\alpha$-amylases belong to GH family 13 , which has a catalytic triad in the TIM barrel catalytic domain and four conserved regions [2].

$\alpha$-Amylases are among the most important industrial enzymes and account for approximately a quarter of the enzyme market [5]. Although $\alpha$-amylases are universally distributed in plants, animals, and microorganisms, microbial $\alpha$-amylases have attracted particular attention because of their wide applications in starch saccharification, baking, brewing, laundry, and textiles, as well as in the pharmaceutical industries [6-8]. $\alpha$-Amylases from extremophiles have been of great interest because they are able to remain active under harsh conditions $[9,10]$. In addition, they offer a good starting point to understand how protein structure relates to function, paving the way for the engineering of 
other enzymes [11, 12]. To date, $\alpha$-amylases from diverse extremophiles, including thermophiles, psychrophiles, acidophiles, alkaliphiles, and halophiles, have been reported [9]. Of these, $\alpha$-amylases from halophiles have attracted increasing interest as they are intrinsically stable and active at high salt concentrations and thus have important potential biotechnological applications in food processing, environmental bioremediation, and pharmaceuticals [13].

Despite their great potential for industrial applications, there have been very limited studies on halophilic $\alpha$-amylases. To date, no more than 20 halophilic $\alpha$-amylases have been purified and characterized from halophilic Archaea, bacteria, and fungi [13]. There are even fewer studies on the gene cloning, overexpression, and characterization of halophilic or halotolerant $\alpha$-amylases [13]. In our previous study, salt-tolerant xylanase and esterase were obtained from soda lake isolate Alkalibacterium sp. SL3 [14, 15]. In this study, an extremely halophilic $\alpha$-amylase-encoding gene (amySL3) was cloned from strain SL3. The $\alpha$-amylase gene was successfully expressed in Escherichia coli and purified by Ni-affinity chromatography. Sequence and function analyses suggested that the recombinant enzyme was extremely halophilic and had some superior properties over the known halophilic $\alpha$-amylases.

\section{Materials and Methods}

\section{Strains, Vectors, and Chemicals}

The donor strain of $\alpha$-amylase gene amySL3, Alkalibacterium sp. SL3, was isolated from the sediment of a soda lake [14]. The strain has been deposited at China General Microbiological Culture Collection Center as CGMCC 1.13866. E. coli Top10 and vector pMD19-T from TaKaRa (Japan) were used for gene cloning. E. coli BL21(DE3) and vector pET-28a (+) from Novagen (USA) were used for gene expression. Kits for genomic DNA extraction, DNA purification, and plasmid isolation were purchased from Omega (USA). T4 DNA ligase, restriction endonucleases, DNA polymerase, and dNTPs were purchased from Thermo Fisher Scientific (USA).
The nickel-nitrilotriacetic acid (NTA) agarose from Qiagen (Germany) was used to purify His $_{6}$-tagged protein. The soluble starch substrate was purchased from Sigma (USA). All other chemicals were of analytical grade and commercially available.

\section{Cloning of the Full-Length $\alpha$-Amylase Gene amySL3}

Genomic DNA of Alkalibacterium sp. SL3 was extracted and purified using the Omega kits following the manufacturer's instructions. Two degenerate primers, amy-F and amy-R, were designed according to the conserved motifs of nine Alkalibacterium $\alpha$-amylases (Table 1). The gene fragment of amySL3 was obtained using the purified genomic DNA as template and the degenerate primer set $a m y-\mathrm{F} /-\mathrm{R}$ designed above. The optimized PCR conditions were: $4 \mathrm{~min}$ at $95^{\circ} \mathrm{C} ; 12$ cycles of $94^{\circ} \mathrm{C}$ for $30 \mathrm{sec}, 60^{\circ} \mathrm{C}$ (decreasing by $0.5^{\circ} \mathrm{C}$ after each cycle) for $30 \mathrm{sec}$, and $72^{\circ} \mathrm{C}$ for $30 \mathrm{sec}$; followed by 28 cycles of $94^{\circ} \mathrm{C}$ for $30 \mathrm{sec}, 54^{\circ} \mathrm{C}$ for $30 \mathrm{sec}$, and $72^{\circ} \mathrm{C}$ for $30 \mathrm{sec}$; and a final extension at $72^{\circ} \mathrm{C}$ for $5 \mathrm{~min}$. The PCR products were excised, purified, and ligated into vector pMD19-T. The recombinant plasmid was then transformed into E. coli Top10, and the objective gene fragment was sequenced by Invitrogen (USA). Because the gene fragment of amySL3 shared $94 \%$ nucleotide sequence identity with the $\alpha$-amylase gene from Alkalibacterium pelagium DSM19183 (NZ_FNZU01000004), primers amySL3-F and amySL3-R were then designed accordingly to amplify the full-length gene of amySL3. The PCR product was obtained and sequenced as described above.

\section{Sequence and Structure Analysis}

DNA and protein sequence similarities were assessed using the BLASTn and BLASTp programs (http://www.ncbi.nlm.nih.gov/ BLAST/), respectively. The signal peptide sequence was predicted using SignalP (http://www.cbs.dtu.dk/services/SignalP/). To obtain the predicted tertiary structure of AmySL3, the protein sequence was directly submitted to I-TASSER [16], one of the best protein structure prediction servers. The top template identified by I-TASSER was 1HVX, the $\alpha$-amylase from Bacillus stearothermophilus [17]; its sequence identity with AmySL3 was 50\% with 99\% coverage. The alignment z-score by MUSTER [18] on the ITASSER server was 23.1, which is significantly higher than the cutoff of 6.1. The prediction was classified as "Easy" by I-TASSER, and the final model was therefore considered to be reliable.

Table 1. Primers used in this study.

\begin{tabular}{llc}
\hline \multicolumn{1}{c}{ Primers } & \multicolumn{1}{c}{ Sequences $\left(5^{\prime} \rightarrow 3^{\prime}\right)^{\mathrm{a}}$} & Size $(\mathrm{bp})$ \\
\hline amy-F & GAGGAGACGAAGAARTGGATHCAYTGG & 27 \\
amy-R & CTCTACGAAAGTNACNGCYTGYTCNGC & 27 \\
amySL3-F & ATGAATGGAACAATGATGCAGTACTTTG & 28 \\
amySL3-R & TTATTCTGTTTTTCTGACCCATACGG & 26 \\
AmySL3-m-F & TTCGAGCTCATGAATGGAACAATGATGCAGTAC & 33 \\
AmySL3-m-R & GTGCTCGAGTTTATTCTGTTTTTCTGACCCATACG & 35 \\
\hline
\end{tabular}

${ }^{\mathrm{a}}$ Restriction sites are bold. 


\section{Expression and Purification of rAmySL3 in E. coli}

An expression primer set (Table 1) was used to amplify the fulllength amySL3, which was then cloned into the SacI-XhoI site of pET-28a (+). The recombinant plasmid, pET-amySL3, was transformed into E. coli BL21 (DE3) competent cells. Expression, purification, and SDS-PAGE analysis of the recombinant $\alpha$-amylase rAmySL3 were performed following the protocol described by Wang et al. [14]. Liquid chromatography-electrospray ionizationtandem mass spectrometry (LC-ESI-MS/MS) was used to identify the purified protein at ProTech (China).

\section{Enzyme Assay}

The $\alpha$-amylase activity was determined using the dinitrosalicylic acid (DNS) method [19]. The standard reaction system contained $0.1 \mathrm{ml}$ of appropriately diluted purified rAmySL3 and $0.9 \mathrm{ml}$ of Mcllvaine buffer $\left(0.2 \mathrm{M} \mathrm{Na}_{2} \mathrm{HPO}_{4}, 0.1 \mathrm{M}\right.$ citric acid, $\left.\mathrm{pH} 7.5\right)$ containing $1 \%(\mathrm{w} / \mathrm{v})$ soluble starch and $4 \mathrm{M} \mathrm{NaCl}$. After incubation at $45^{\circ} \mathrm{C}$ for $10 \mathrm{~min}$, reactions were terminated by the addition of $1.5 \mathrm{ml}$ of DNS reagent and a $5 \mathrm{~min}$-boiling water bath. The amount of reducing sugar was determined spectrophotometrically at $540 \mathrm{~nm}$. Maltose was used to generate a standard curve. One unit (U) of $\alpha$-amylase activity was defined as the amount of enzyme that released $1 \mu \mathrm{mol}$ of reducing sugar equivalent to maltose per minute. All reactions were performed in triplicate.

\section{Biochemical Characterization}

The substrate specificity of rAmySL3 was determined in Mcllvaine buffer $(\mathrm{pH} 7.5$ ) containing $1 \%$ of substrate under standard conditions $\left(45^{\circ} \mathrm{C}, 10 \mathrm{~min}\right)$. The substrates used were soluble starch, amylose, amylopectin, pullulan, glycogen, corn starch, potato starch, and tapioca starch.

The optimal $\mathrm{pH}$ of rAmySL3 was determined at $37^{\circ} \mathrm{C}$ in buffers with $\mathrm{pH}$ ranging from 4.0 to 9.0 . The $\mathrm{pH}$ stability was estimated by measuring the rAmySL3 activity under standard conditions ( $\mathrm{pH} 7.5,45^{\circ} \mathrm{C}$ and $10 \mathrm{~min}$ ) after 1 h-incubation at $\mathrm{pH} 4.0$ to 10.0 and $37^{\circ} \mathrm{C}$ without substrate. The initial rAmySL3 activity was set to $100 \%$. The buffers used were McIlvaine buffer ( $\mathrm{pH} 4.0-8.0$ ), $0.1 \mathrm{M}$ Tris- $\mathrm{HCl}$ ( $\mathrm{pH} 8.0-9.0)$, and $0.1 \mathrm{M}$ glycine- $\mathrm{NaOH}$ ( $\mathrm{pH} 9.0-$ 10.0). The optimal temperature of rAmySL3 was determined in Mcllvaine buffer ( $\mathrm{pH} 7.5$ ) over the temperature range of $5^{\circ} \mathrm{C}$ to $70^{\circ} \mathrm{C}$ for $10 \mathrm{~min}$. The thermostability was determined by measuring the residual activity under standard conditions after pre-incubation of the enzyme in Mcllvaine buffer $(\mathrm{pH} 7.5)$ at $35^{\circ} \mathrm{C}, 40^{\circ} \mathrm{C}, 45^{\circ} \mathrm{C}$, and $50^{\circ} \mathrm{C}$ for various durations.

For kinetic analysis, the enzymatic activities of rAmySL3 were assayed in Mcllvaine buffer ( $\mathrm{pH}$ 7.5) containing 1-10 mg/ml soluble starch at $45^{\circ} \mathrm{C}$ for $5 \mathrm{~min}$. The $K_{m}, V_{\max }$, and $k_{\text {cat }}$ values were determined using the non-linear regression program GraFit (Erithacus, Horley, UK).

The effect of metal ions, surfactants, and organic solvents on rAmySL3 activity and stability was also determined. The rAmySL3 thermostability in the presence of $4 \mathrm{M} \mathrm{NaCl}$ was assayed at 45 and $50^{\circ} \mathrm{C}$ as described above. The salt-stability was determined in the presence of 4 or $5 \mathrm{M} \mathrm{NaCl}$ at $37^{\circ} \mathrm{C}$. The effect of $\mathrm{Na}^{+}, \mathrm{Ca}^{2+}$, ethylenediaminetetraacetic acid (EDTA), Triton X-100, Tween-20, Tween-80, methanol, ethanol, butanol, isobutanol, isoamyl alcohol, acetone, glycerol, $n$-hexane, and chloroform on rAmySL3 activity was determined at $45^{\circ} \mathrm{C}$ in McIlvaine buffer (pH 7.5) containing 0-5.0 M NaCl, 0-20 mM CaCl ${ }_{2}, 0-100 \mathrm{mM}$ EDTA, 5 or $10 \%(\mathrm{v} / \mathrm{v})$ surfactant, or 20 or $50 \%(\mathrm{v} / \mathrm{v})$ organic solvent. To determine the interacted effect of EDTA and calcium ion on rAmySL3 activity, the purified enzyme was treated with $100 \mathrm{mM}$ EDTA for $30 \mathrm{~min}$ at $4^{\circ} \mathrm{C}$, followed by three-time dialysis in Tris- $\mathrm{HCl}$ buffer ( $\mathrm{pH}$ 7.5). The EDTA-treated enzyme was then subjected to amylase activity assay in the presence of $0,0.1,0.5,1$, 2 , or $5 \mathrm{mM} \mathrm{CaCl}_{2}$. The effect of SDS on rAmySL3 activity was also tested at the concentrations of $0.1 \%$ and $1 \%$ with $2 \mathrm{M} \mathrm{NaCl}$ (SDS will salt out when its concentration is higher than $1 \%$ in the presence of $2 \mathrm{M} \mathrm{NaCl}$ ). The enzyme activity without any addition was defined as $100 \%$.

\section{Hydrolysis Product Analysis}

Purified rAmySL3 was mixed with 1\% (w/v) of each substrate (soluble starch, amylose, amylopectin, corn starch, potato starch, and tapioca starch) in Mcllvaine buffer ( $\mathrm{pH} 7.5)$ and incubated at $45^{\circ} \mathrm{C}$ for $24 \mathrm{~h}$. Thin-layer chromatography (TLC) with the silica gel G-60 and a solvent system of butanol, ethanol, and water (5:3:2, $\mathrm{v} / \mathrm{v} / \mathrm{v}$ ) was used to analyze the hydrolysis products. Carbohydrate products were visualized by spraying with a mixture of $1 \%(\mathrm{v} / \mathrm{v})$ aniline, $1 \%(\mathrm{w} / \mathrm{v})$ diphenylamine, and $5 \%(\mathrm{v} / \mathrm{v})$ phosphoric acid in acetone. Glucose $(\mathrm{G})$, maltose (G2), maltotriose (G3), maltotetraose (G4), maltopentaose (G5), maltohexaose (G6), and maltoheptaose (G7) were used as standards.

\section{Results}

\section{Sequence and Structure Analysis of amySL3}

A full-length $\alpha$-amylase gene (amySL3; GenBank Accession No. MH763825) of 1,455 bp was successfully cloned from Alkalibacterium sp. SL3. amySL3 encodes a polypeptide of 484 amino acid residues with a calculated mass of $56.6 \mathrm{kDa}$ and a theoretical isoelectric point of 4.56 . No signal peptide was predicted by the SignalP. The deduced amino acid sequence of amySL3 has the highest identities with putative $\alpha$-amylases from Alkalibacterium: $98 \%$ with $A$. pelagium (WP_091479515.1), 97\% with A. thalassium (WP_091267104.1), 93\% with A. olivapovliticus (WP_106194330.1), 83\% with A. putridalgicola (WP_091487088.1), 83\% with Alkalibacterium sp. AK22 (WP_034301409.1), and 82\% with A. gilvum (WP_091633519.1), but shares low sequence identities (33$53 \%$ ) with functionally characterized $\alpha$-amylases from Bacillus amyloliquefaciens [20] and other halophilic $\alpha$-amylases (Table 2). Deduced AmySL3 belongs to GH family 13, containing four highly conserved regions [2] and three 
Table 2. Enzymatic characteristics and amino acid compositions of AmySL3 and other halophilic or halotolerant counterparts.

\begin{tabular}{|c|c|c|c|c|c|c|c|c|c|c|c|c|c|}
\hline Enzyme & Microbial source & Characteristic & $\begin{array}{l}\mathrm{T}_{\text {opt }} \\
\left({ }^{\circ} \mathrm{C}\right)\end{array}$ & $\mathrm{pH}_{\text {opt }}$ & $\begin{array}{l}\mathrm{NaCl}_{\text {opt }} \\
(\mathrm{M})\end{array}$ & $\begin{array}{l}\text { Specific } \\
\text { activity } \\
\left(\mathrm{U} \mathrm{mg}^{-1}\right)^{\mathrm{a}}\end{array}$ & $\begin{array}{c}K_{m} \\
\left(\mathrm{mg} \mathrm{ml}^{-1}\right)\end{array}$ & $\begin{array}{c}V_{\max } \\
\left(\mu \mathrm{mol} \mathrm{mg^{-1 }} \min ^{-1}\right)\end{array}$ & $\begin{array}{l}k_{\text {cat }} \\
\left(\mathrm{s}^{-1}\right)\end{array}$ & $\begin{array}{c}\text { Asp+Glu } \\
(\%)\end{array}$ & $\begin{array}{c}\text { Lys+Arg } \\
(\%)\end{array}$ & $\begin{array}{l}\text { Hydrophobic } \\
\text { amino acids } \\
(\%)^{\mathrm{b}}\end{array}$ & Reference \\
\hline AmySL3 & $\begin{array}{l}\text { Alkalibacterium } \\
\text { sp. SL3 }\end{array}$ & Halophilic & 45 & 7.5 & 5.0 & 313.9 & 3.6 & 527.5 & 497.7 & 20.7 & 8.9 & 30.0 & This study \\
\hline AmyHh & $\begin{array}{l}\text { Haloarcula } \\
\text { hispanica }\end{array}$ & Halophilic & 50 & 7.5 & 4.0 & - & - & - & - & 16.5 & 6.1 & 32.9 & [25] \\
\hline AmyHj & $\begin{array}{l}\text { Haloarcula } \\
\text { japonica }\end{array}$ & Halophilic & 45 & 6.5 & 2.6 & 24 & - & - & - & 18.3 & 7.5 & 35.1 & [39] \\
\hline AmyN & $\begin{array}{l}\text { Natronococcus } \\
\text { sp. Ah-36 }\end{array}$ & Halophilic & 55 & 8.7 & 2.5 & 160 & 25 & - & - & 24.2 & 5.4 & 32.8 & [38] \\
\hline AmyEc & $\begin{array}{l}\text { Escherichia coli } \\
\text { JM109 }\end{array}$ & Halophilic & 55 & 7.0 & 2.0 & 1090 & 4.3 & 909 & 825 & 17.0 & 8.1 & 35.4 & [40] \\
\hline AmyKv & $\begin{array}{l}\text { Kocuria } \\
\text { varians }\end{array}$ & Halophilic & - & - & 2.0 & 273 & - & - & - & 16.9 & 3.8 & 33.7 & [21] \\
\hline AmyHt & $\begin{array}{l}\text { Haloterrigena } \\
\text { turkmenica }\end{array}$ & Halophilic & 55 & 8.5 & 2.0 & 79.8 & - & - & - & 18.2 & 6.1 & 31.0 & [33] \\
\hline AmyHm & $\begin{array}{l}\text { Halomonas } \\
\text { meridiana }\end{array}$ & Halophilic & 37 & 7.0 & 1.7 & - & - & - & - & 12.5 & 5.5 & 34.8 & [41] \\
\hline AmyZp & $\begin{array}{l}\text { Zunongwangia } \\
\text { profunda }\end{array}$ & Halotolerant & 35 & 7.0 & 1.5 & 275.8 & 2.7 & 287.7 & 316.5 & 15.5 & 9.8 & 28.6 & [27] \\
\hline AmyP & $\begin{array}{l}\text { Pseudoalteromonas } \\
\text { sp. M175 }\end{array}$ & Halotolerant & 25 & 8.0 & 1.0 & 337.9 & 2.5 & 0.125 & - & 13.3 & 8.4 & 34.4 & [29] \\
\hline AmyHo & $\begin{array}{l}\text { Halothermothrix } \\
\text { orenii }\end{array}$ & Halotolerant & 65 & 7.5 & 0.9 & 22.3 & - & - & - & 14.5 & 10.8 & 31.8 & [42] \\
\hline AmyPh & $\begin{array}{l}\text { Alteromonas } \\
\text { haloplanctis A23 }\end{array}$ & Halotolerant & 25 & 7.0 & 0.5 & - & - & - & - & 10.5 & 6.1 & 31.9 & [43] \\
\hline
\end{tabular}

${ }^{a}$ The specific activities of amylase AmyHj and AmyHt were determined using the method of iodine-starch; the specific activities of amylase AmyN and AmyKv were determined by the method of Somogyi-Nelson; the specific activities of amylase AmySL3, AmyEc, AmyZp, AmyP and AmyHo were determined by the method of DNS.

Including Ala, Ile, Leu, Phe, Trp, and Val.

- , not determined 


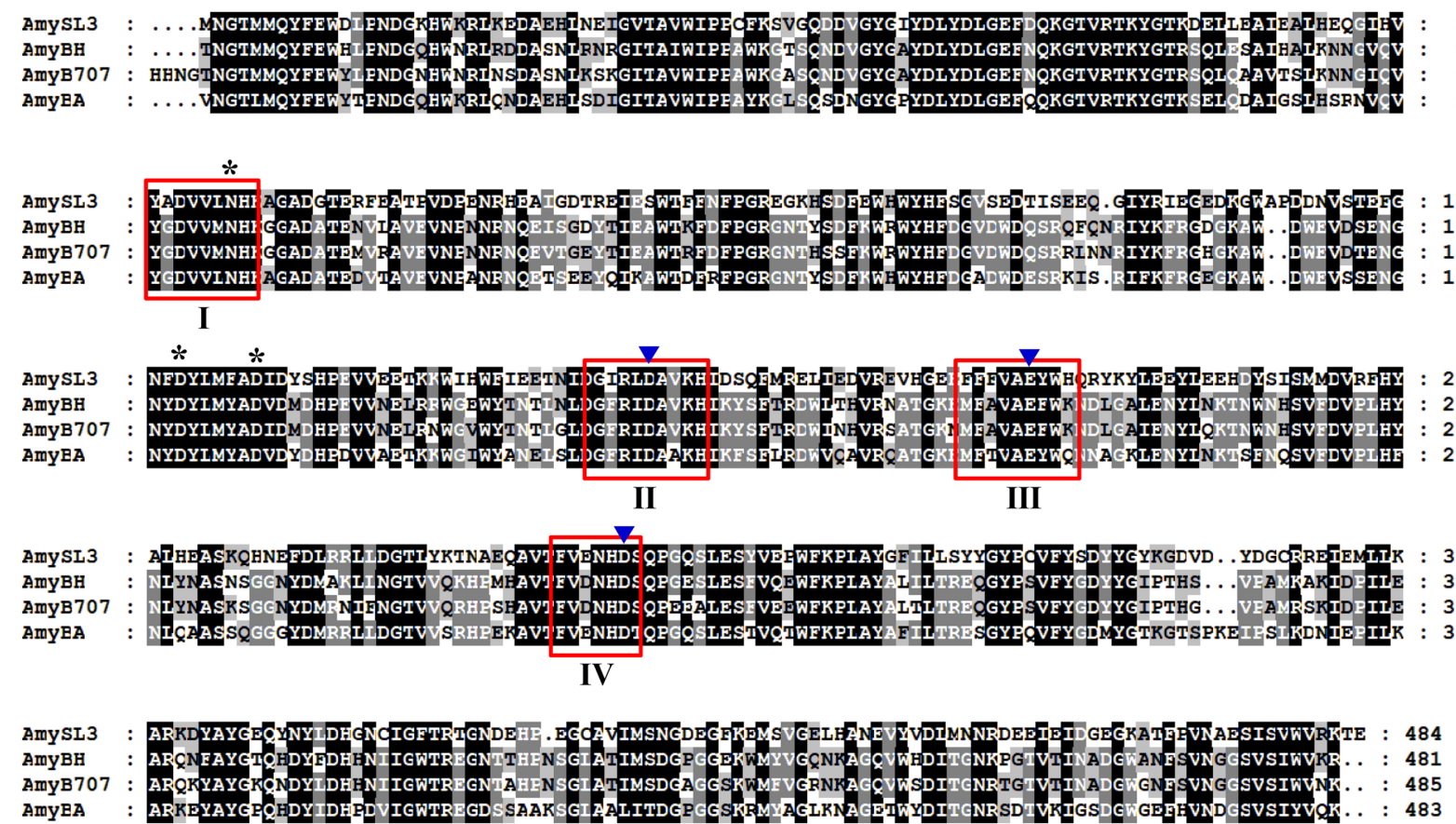

Fig. 1. Multiple sequence alignment of AmySL3 and three other GH13 $\alpha$-amylases.

Identical and similar amino acids are highlighted in solid black and grey, respectively. The four conserved regions (I, II, III, and IV) are boxed. The

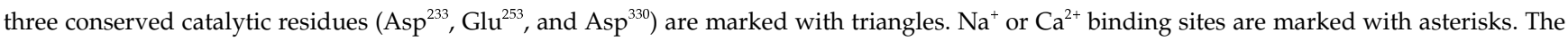
sequence name, microbial source, and GenBank accession numbers of each $\alpha$-amylase are shown as follows: AmySL3, Alkalibacterium sp. SL3 (this study); AmyBH, Bacillus halmapalus (WP_078382693); AmyB707, Bacillus sp. 707 (P19571); and AmyBA, Bacillus amyloliquefaciens (WP_013352208).

putative catalytic residues, $\mathrm{Asp}^{233}, \mathrm{Glu}^{253}$, and $\mathrm{Asp}^{330}$, which form the catalytic triad (Fig. 1).

The amino acid composition of AmySL3 was analyzed and compared with those of ten halophilic or halotolerant $\alpha$-amylases (Table 2). AmySL3 is distinguished by high Asp+Glu content $(20.7 \%)$ and low hydrophobic amino acid content $(30.0 \%)$. Using 1HVX [17] as the template, homology-modeled AmySL3 has the typical $(\beta / \alpha)_{8}$ barrel structure of GH family 13 proteins (Figs. $2 \mathrm{~A}$ and $2 \mathrm{~B}$ ). Surface electrostatic potential analysis indicated that most acid amino acid residues are distributed on the surface of AmySL3 (Figs. 2C and 2D).

\section{Expression and Purification of rAmySL3}

After induction with $1 \mathrm{mM}$ IPTG at $30^{\circ} \mathrm{C}$ for $12 \mathrm{~h}$, significant $\alpha$-amylase activity was detected in the cell lysate. The purified rAmySL3 migrated as a single band on SDS-PAGE (Fig. 3), but had a molecular mass slightly higher than the calculated value $(56.6 \mathrm{kDa})$. Similar migration has been reported in the halophilic $\alpha$-amylase from moderately halophilic bacterium Kocuria varians [21]. Three internal peptides obtained by LC-ESI-MS/MS,

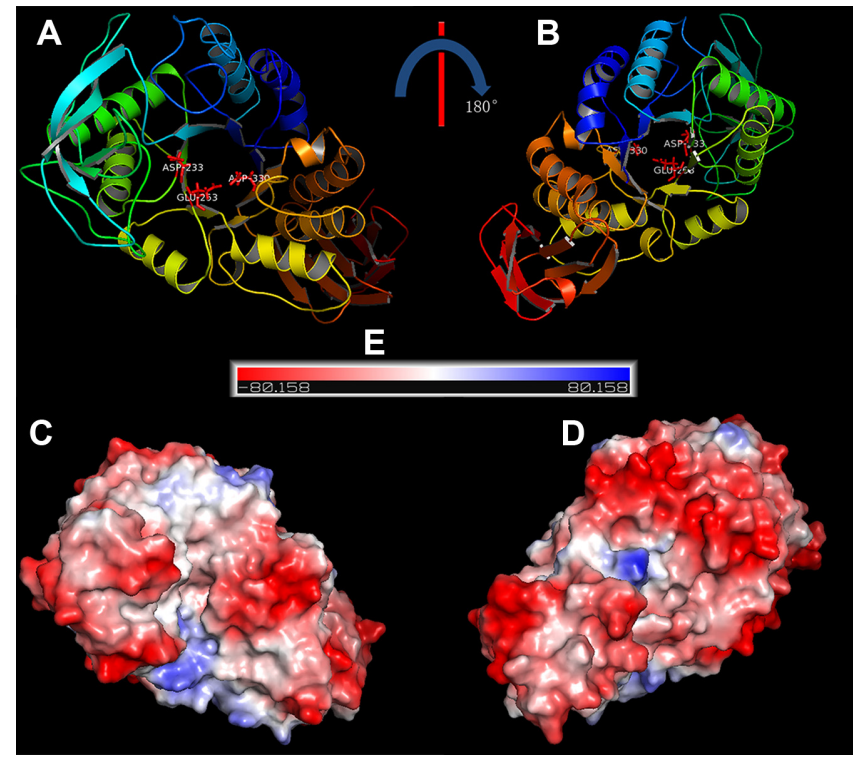

Fig. 2. The tertiary structure and corresponding electrostatic potentials of the homology-modeled AmySL3.

(A) and (B) show top and bottom views of the model, respectively. (C) and (D) show surface electrostatic potentials for (A) and (B), respectively. The negative and positive electrostatic potentials are indicated by red and blue, respectively. 


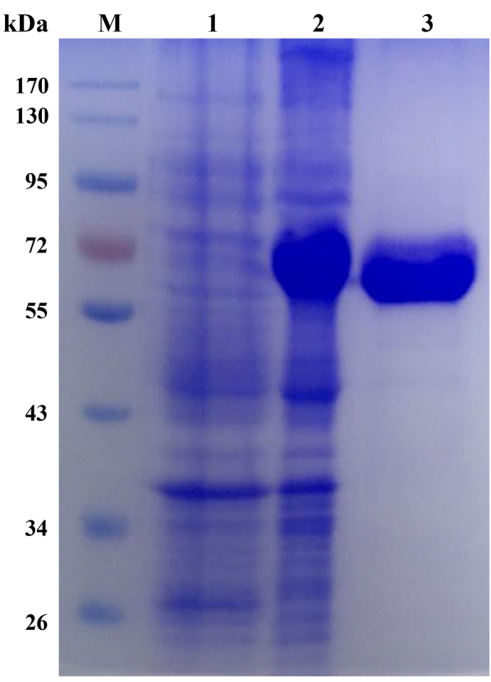

Fig. 3. SDS-PAGE analysis of the purified rAmySL3.

Lanes: $\mathrm{M}$, the molecular-weight protein marker; 1 , the cell lysate of an uninduced transformant harboring pET-amySL3; 2, the cell lysate of an induced transformant harboring pET-amySL3; and 3, the purified rAmySL3 after Ni-affinity chromatography.
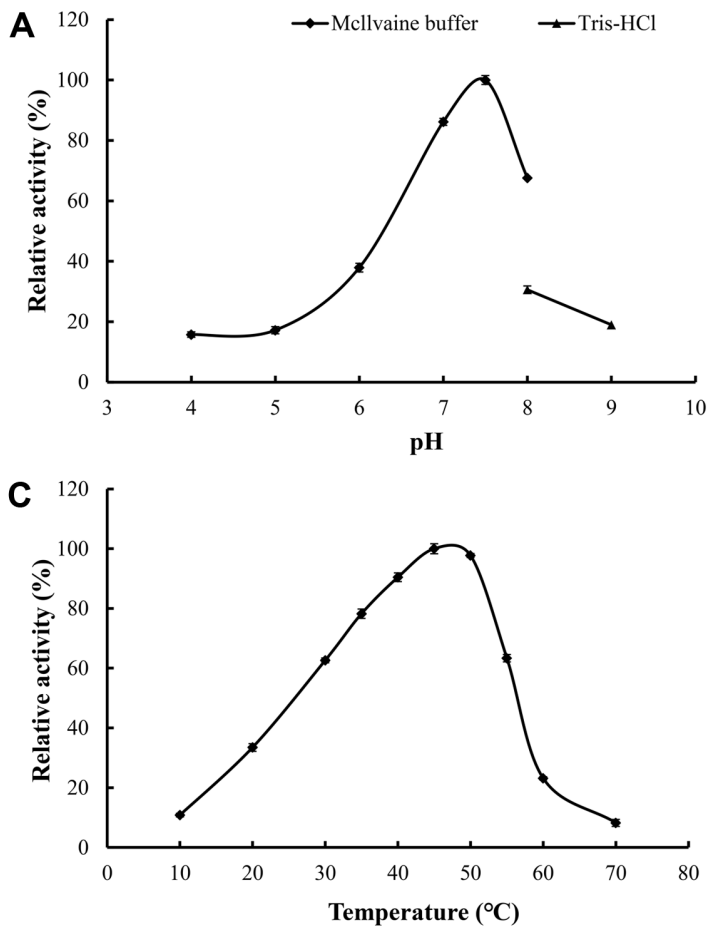

SVGQDDVGYGIYDLYDLGEFDQK, PLAYGFILLSYYGYP CVFYSDYYGYK, and EMSVGELHANEVYVDLMNNR, matched the deduced amino acid sequence of AmySL3. The specific activity of purified rAmySL3 towards soluble starch was determined to be $313.9 \mathrm{U} / \mathrm{mg}$.

\section{Enzyme Characterization}

The $\mathrm{pH}$ and temperature properties of rAmySL3 were determined using soluble starch as the substrate. rAmySL3 showed the highest activity at $\mathrm{pH} 7.5$, and more than $60 \%$ of the maximum activity remained between $\mathrm{pH} 6.5$ and 8.0 (Fig. 4A). The enzyme was stable between $\mathrm{pH} 6.5$ and 10.0 , retaining more than $50 \%$ of its initial activity after incubation at $37^{\circ} \mathrm{C}$ for $1 \mathrm{~h}$ (Fig. $4 \mathrm{~B}$ ). rAmySL3 was apparently optimal at $45^{\circ} \mathrm{C}$ when assayed at $\mathrm{pH} 7.5$, and it retained more than $50 \%$ of its maximum activity when assayed at $25-55^{\circ} \mathrm{C}$ (Fig. $4 \mathrm{C}$ ). Without $\mathrm{NaCl}$, the enzyme was stable at $35^{\circ} \mathrm{C}$ and $40^{\circ} \mathrm{C}$ for more than $1 \mathrm{~h}$, but lost $50 \%$ activity at $45^{\circ} \mathrm{C}$ and $50^{\circ} \mathrm{C}$ after $20 \mathrm{~min}$ and $7 \mathrm{~min}$ (Fig. $4 \mathrm{D}$ ), respectively.
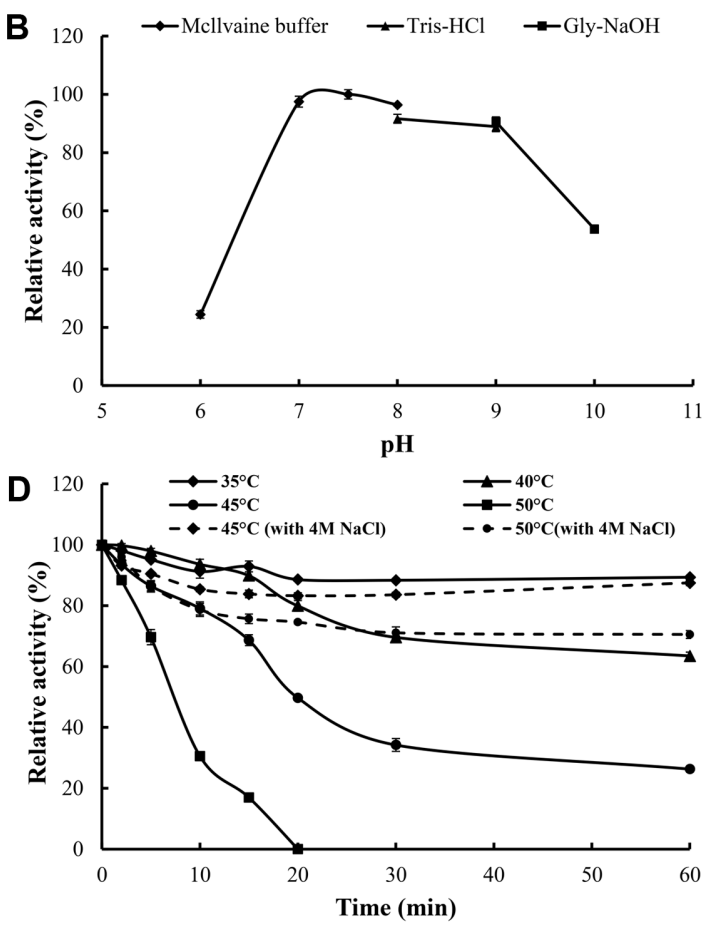

Fig. 4. Enzymatic properties of the purified rAmySL3.

(A) Effect of $\mathrm{pH}$ on rAmySL3 activity. Activities at various $\mathrm{pH}$ values were assayed at $37^{\circ} \mathrm{C}$ for $10 \mathrm{~min}$ in the presence of $4 \mathrm{M} \mathrm{NaCl}$. (B) $\mathrm{pH}$ stability of rAmySL3. Residual activities after incubation of the purified enzyme at various $\mathrm{pH}$ values for $1 \mathrm{~h}$ at $37^{\circ} \mathrm{C}$ were assayed at $\mathrm{pH} 7.5,45^{\circ} \mathrm{C}$, and $4 \mathrm{M}$ $\mathrm{NaCl}$ for $10 \mathrm{~min}$. (C) Effect of temperature on rAmySL3 activity in McIlvaine buffer (pH 7.5, $4 \mathrm{M} \mathrm{NaCl}$ ). (D) Thermostability of rAmySL3. Residual activities were assayed at $\mathrm{pH} 7.5,45^{\circ} \mathrm{C}$ and $4 \mathrm{M} \mathrm{NaCl}$ for $10 \mathrm{~min}$ after pre-incubation at $35^{\circ} \mathrm{C}, 40^{\circ} \mathrm{C}, 45^{\circ} \mathrm{C}$, and $50^{\circ} \mathrm{C}$ without $\mathrm{NaCl}$ for different periods of time. Thermostability of rAmySL 3 at $45^{\circ} \mathrm{C}$ and $50^{\circ} \mathrm{C}$ in the presence of $4 \mathrm{M} \mathrm{NaCl}$ was also assayed. Each value in the panel represents the mean $\pm \mathrm{SD}(n=3)$. 

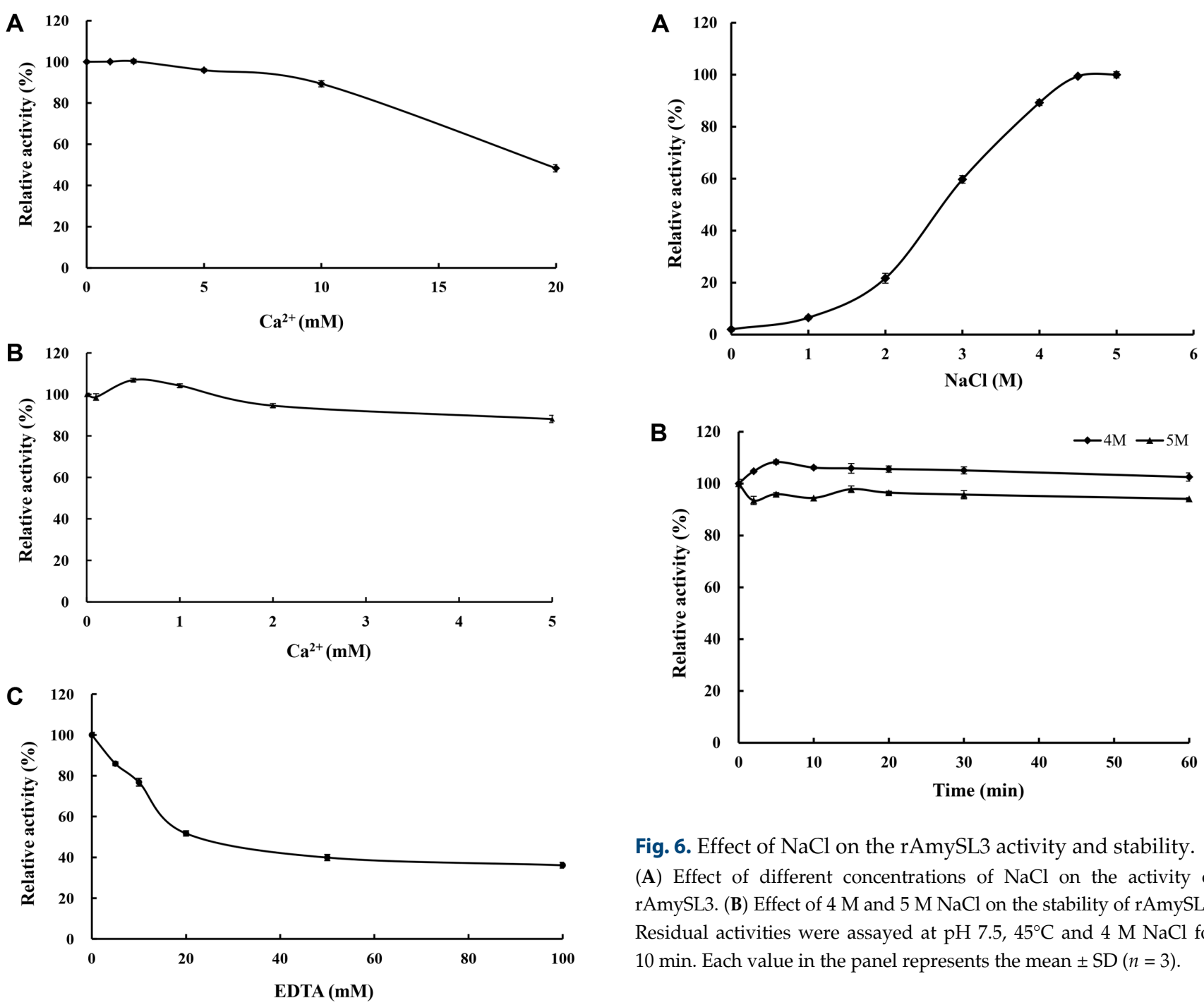

Fig. 6. Effect of $\mathrm{NaCl}$ on the rAmySL3 activity and stability. (A) Effect of different concentrations of $\mathrm{NaCl}$ on the activity of rAmySL3. (B) Effect of $4 \mathrm{M}$ and $5 \mathrm{M} \mathrm{NaCl}$ on the stability of rAmySL3. Residual activities were assayed at $\mathrm{pH} 7.5,45^{\circ} \mathrm{C}$ and $4 \mathrm{M} \mathrm{NaCl}$ for $10 \mathrm{~min}$. Each value in the panel represents the mean $\pm \mathrm{SD}(n=3)$.

Fig. 5. Effect of $\mathrm{CaCl}_{2}$ and EDTA on the rAmySL3 activity. (A) The effect of $0-20 \mathrm{mM} \mathrm{CaCl}_{2}$ on the activity of rAmySL3. (B) The effect of $0-5 \mathrm{mM} \mathrm{CaCl}_{2}$ on the activity of EDTA-treated rAmySL3. (C) The effect of 0-100 mM EDTA on the activity of rAmySL3. Activities were assayed at $\mathrm{pH} 7.5,45^{\circ} \mathrm{C}$ and $4 \mathrm{M} \mathrm{NaCl}$ for $10 \mathrm{~min}$. Each value in the panel represents the mean $\pm \mathrm{SD}(n=3)$.

Using soluble starch as the substrate, the $K_{m}, V_{\max }$ and $k_{\text {cat }}$ values were $3.6 \pm 0.2 \mathrm{mg} / \mathrm{ml}, 527.5 \pm 12.3 \mu \mathrm{mol} \mathrm{mg} / \mathrm{min}$, and $497.7 \pm 11.6 \mathrm{~s}^{-1}$, respectively.

The effect of $\mathrm{CaCl}_{2}$ and EDTA on rAmySL3 activity was investigated. As shown in Fig. 5A, low concentrations $(<2$ $\mathrm{mM}$ ) of $\mathrm{CaCl}_{2}$ had no effect on the activity of rAmySL3, while high concentrations $(>10 \mathrm{mM})$ of $\mathrm{CaCl}_{2}$ obviously inhibited the activity. EDTA-treated enzyme retained high activity when $\mathrm{CaCl}_{2}$ was absent (Fig. 5B). EDTA alone

inhibited the rAmySL3activity (Fig. 5C), causing an activity reduction of $14 \%$ at $5 \mathrm{mM}$ and $64 \%$ at $100 \mathrm{mM}$, respectively.

\section{Extremely Halophilic and Salt-Dependent Stability}

The effect of $\mathrm{NaCl}$ on rAmySL3 activity and stability was also investigated. As shown in Fig. 6A, rAmySL3 lost $\alpha$-amylase activity without $\mathrm{NaCl}$, but showed increased activity along with the increased concentration of $\mathrm{NaCl}$ up to $5.0 \mathrm{M}$. Moreover, rAmySL3 was highly stable at high concentrations of $\mathrm{NaCl}$, retaining more than $90 \%$ activity after a $1 \mathrm{~h}$-incubation at $37^{\circ} \mathrm{C}$ and $\mathrm{pH} 7.5$ with $4 \mathrm{M}$ or $5 \mathrm{M}$ $\mathrm{NaCl}$ (Fig. 6B). The thermostability of rAmySl3 was improved in the presence of $4 \mathrm{M} \mathrm{NaCl}$. After incubation at $\mathrm{pH} 7.5$ and 45 or $50^{\circ} \mathrm{C}$ for $1 \mathrm{~h}$, the enzyme retained $87 \%$ and $71 \%$ of its initial activity (Fig. 4D), respectively. Under the same conditions, it lost $74-100 \%$ activity without $\mathrm{NaCl}$. 
Table 3. Effects of various surfactants and organic solvents on the activity of the purified rAmySL3.

\begin{tabular}{|c|c|c|c|c|c|}
\hline Chemicals & Concentration (\%) & Relative activity $(\%)^{a}$ & Chemicals & Concentration (\%) & Relative activity (\%) \\
\hline \multirow[t]{2}{*}{ Control } & 0 & $100.0 \pm 0.0$ & Butanol & 20 & $88.6 \pm 2.5$ \\
\hline & & & & 50 & $5.4 \pm 0.0$ \\
\hline \multirow[t]{2}{*}{ Tween-20 } & 5 & $103.7 \pm 2.9$ & Isobutanol & 20 & $90.7 \pm 0.9$ \\
\hline & 10 & $115.2 \pm 4.1$ & & 50 & $9.5 \pm 1.3$ \\
\hline \multirow[t]{2}{*}{ Tween-80 } & 5 & $95.9 \pm 1.5$ & Isoamyl alcohol & 20 & $89.8 \pm 0.6$ \\
\hline & 10 & $117.3 \pm 1.9$ & & 50 & $38.0 \pm 1.1$ \\
\hline \multirow[t]{2}{*}{ Triton X-100 } & 5 & $102.3 \pm 0.0$ & Acetone & 20 & $6.6 \pm 0.9$ \\
\hline & 10 & $81.5 \pm 1.3$ & & 50 & ND \\
\hline \multirow[t]{2}{*}{ SDS } & 0.1 & $40.2 \pm 0.8$ & Glycerol & 20 & $85.8 \pm 0.2$ \\
\hline & 1 & $11.0 \pm 0.6$ & & 50 & $73.8 \pm 2.9$ \\
\hline \multirow[t]{2}{*}{ Methanol } & 20 & ND & n-Hexane & 20 & $90.0 \pm 0.5$ \\
\hline & 50 & ND & & 50 & $95.9 \pm 0.3$ \\
\hline \multirow[t]{2}{*}{ Ethanol } & 20 & $3.3 \pm 0.3$ & Chloroform & 20 & $85.1 \pm 0.4$ \\
\hline & 50 & $3.8 \pm 0.3$ & & 50 & $83.2 \pm 0.6$ \\
\hline
\end{tabular}

${ }^{a}$ The AmySL3 activity was assayed in the reaction systems containing $0.1 \mathrm{ml}$ of appropriately diluted purified rAmySL3, $0.9 \mathrm{ml} \mathrm{Mcllvaine} \mathrm{buffer} \mathrm{(pH} \mathrm{7.5),} 1 \mathrm{M} \mathrm{NaCl}$, and different concentrations of chemical reagent at $45^{\circ} \mathrm{C}$. The specific activity $\left(307.6 \mathrm{U} \mathrm{mg}^{-1}\right)$ without any reagent was defined as $100 \%$. The data are shown as means $\pm \mathrm{SD}(n=3)$. ND, not detected.

\section{Tolerance to Various Surfactants and Organic Solvents}

The tolerance of rAmySL3 against various surfactants and organic solvents was determined (Table 3). Of the four surfactants tested, Tween-20 and Tween- 80 had no obvious effects on rAmySL3 activity at the concentration of $5 \%(\mathrm{v} / \mathrm{v})$, but enhanced the activity by more than $15 \%$ at the concentration of $10 \%(\mathrm{v} / \mathrm{v})$. The enzyme was also highly resistant to Triton $\mathrm{X}-100$, retaining more than $80 \%$ of its initial activity at the concentrations of 5 and $10 \%(\mathrm{v} / \mathrm{v})$. However, rAmySL3 was highly sensitive towards SDS, retaining approximately $40 \%$ and $11 \%$ of its initial activity at the concentrations of $0.1 \%$ and $1 \%(\mathrm{~m} / \mathrm{v})$, respectively. Of the tested organic solvents, rAmySL3 activity was greatly inhibited by methanol, ethanol, and acetone and high concentration $(50 \%)$ of butanol, isobutanol, and isoamyl alcohol. Moreover, rAmySL3 was highly tolerant to hydrophobic solvents, retaining more than $70 \%$ activity in the presence of n-hexane and chloroform at concentrations up to $50 \%$.
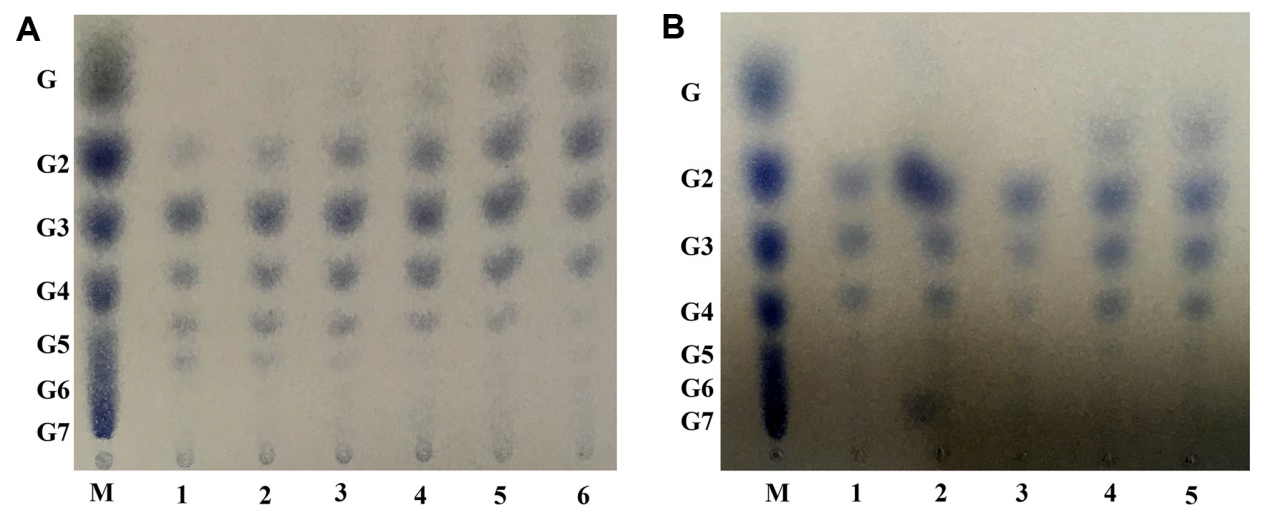

Fig. 7. TLC analysis of the hydrolysis products generated by rAmySL3.

(A) Hydrolysis products generated from soluble starch at $\mathrm{pH} 7.5,45^{\circ} \mathrm{C}$ and $4 \mathrm{M} \mathrm{NaCl}$. Samples were taken at $30 \mathrm{~min}$ (lane 1), $1 \mathrm{~h}$ (lane 2), $2 \mathrm{~h}$ (lane 3), $4 \mathrm{~h}$ (lane 4), $8 \mathrm{~h}$ (lane 5), and $24 \mathrm{~h}$ (lane 6), respectively. (B) Hydrolysis products generated from potato starch (lane 1), corn starch (lane 2), tapioca starch (lane 3), amylopectin (lane 4), and amylose (lane 5) after $24 \mathrm{~h}$ incubation. Lane $\mathrm{M}$, the standard of malto-oligosaccharides. G, glucose; G2, maltose; G3, maltotriose; G4, maltotetraose; G5, maltopentaose; G6, maltohexaose; and G7, maltoheptaose. 


\section{Substrate Specificity and Hydrolysis Product Analysis}

rAmySL3 had high specific activities towards soluble starch $(313.9 \mathrm{U} / \mathrm{mg})$, tapioca starch $(291.4 \mathrm{U} / \mathrm{mg})$, amylopectin $(213.7 \mathrm{U} / \mathrm{mg})$, potato starch $(191.6 \mathrm{U} / \mathrm{mg})$, and corn starch $(120.3 \mathrm{U} / \mathrm{mg})$. It had weak activity towards amylose $(38.6 \mathrm{U} / \mathrm{mg})$ and glycogen $(37.8 \mathrm{U} / \mathrm{mg})$, and no activity against pullulan. It suggests that AmySL3 is specific on the cleavage of $\alpha-1,4$-glucosidic bonds.

The hydrolysis products of various substrates by rAmySL3 were determined by TLC. The major hydrolysis products of soluble starch were maltose and maltotriose, plus a small proportion of glucose and maltotetraose (Fig. 7A). With potato starch, corn starch, and tapioca starch as the substrate, the major hydrolysis products were composed of maltobiose, maltotriose, and maltotetraose; while the products from amylopectin and amylose were mainly maltose and maltotriose (Fig. 7B).

\section{Discussion}

A soda lake represents a unique habitat which is characterized by both high alkalinity and high salinity, and harbors a rich diversity of novel enzyme-producing microorganisms [22]. Alkalibacterium sp. SL3 was isolated from the sediment of a typical soda lake with high salinity and alkalinity [23]. In our previous study, a cold-adapted and highly salt-tolerant esterase and a salt-stable alkaline xylanase have been obtained from this strain [14, 15]. In this study, a new $\alpha$-amylase gene, amySL3, was cloned from strain SL3. Although deduced AmySL3 has high similarity to those putative amylases from Alkalibacterium, none of them has been functionally characterized. The low identities $(<53 \%)$ of AmySL3 with functionally characterized $\alpha$-amylase and halophilic or halotolerant counterparts (Table 2) suggest that the AmySL3 from Alkalibacterium sp. SL3 is a new $\alpha$-amylase with great research and application potential.

One characteristic feature of halophilic enzymes is that they require high salt concentrations for activity and stability [13]. rAmySL3 under study was adaptable to high concentrations of $\mathrm{NaCl}$ up to $5 \mathrm{M}$ (Fig. 6A), and remained stable in the presence of $5 \mathrm{M} \mathrm{NaCl}$ (Fig. 6B). The enzyme lost activity without $\mathrm{NaCl}$, and its thermostability was greatly enhanced by $4 \mathrm{M} \mathrm{NaCl}$ (Fig. 4D). These results suggested that rAmySL3 is an extremely halophilic $\alpha$-amylase. Extremely halophilic $\alpha$-amylases are mainly from halophilic Archaea. For example, the halophilic $\alpha$-amylase from Haloarcula sp. strain S-1 exhibited maximal activity at $4.3 \mathrm{M} \mathrm{NaCl}$ [24]; the halophilic $\alpha$-amylase $\mathrm{AmyH}$ from Haloarcula hispanica exhibited maximal activity at 4$5 \mathrm{M} \mathrm{NaCl}$ [25]; and the polyextremophilic $\alpha$-amylase from Halorubrum xinjiangense exhibited maximal activity at $4 \mathrm{M}$ $\mathrm{NaCl}$ [26]. In contrast, halophilic or halotolerant $\alpha$-amylases from bacteria have an optimal salinity of lower than $3 \mathrm{M}$ [13]. To the best of our knowledge, rAmySL3 is the first bacterial $\alpha$-amylase with an optimal salinity of up to $5 \mathrm{M}$ $\mathrm{NaCl}$ (nearly saturated).

To date, only the $\alpha$-amylases from marine bacteria Pseudoalteromonas haloplanktis [27], Zunongwangia profunda [28], and Pseudoalteromonas sp. M175 [29] were found to be both cold-active and halotolerant. rAmySL3 showed its maximum activity at $45^{\circ} \mathrm{C}$, which is higher than the optimal temperature of three cold-active and halotolerant $\alpha$-amylases, but lower than that of most other reported halophilic or halotolerant $\alpha$-amylases (Table 2). Although rAmySL3 is not a cold-active enzyme, it retained more than $60 \%$ and $33 \%$ relative activity at $30^{\circ} \mathrm{C}$ and $20^{\circ} \mathrm{C}$, respectively. In addition, the specific activity of rAmySL3 towards soluble starch is $313.9 \mathrm{U} / \mathrm{mg}$, which is lower than the halophilic amylase AmyEc from Escherichia coli JM109 and the halotolerant $\alpha$-amylase AmyP from Pseudoalteromonas sp. M175, but higher than most other halophilic or halotolerant $\alpha$-amylases (Table 2). These results suggest that rAmySL3 has application potential in industries where low temperature and high salinity are required [30].

Calcium ion functions as an activator for most halophilic $\alpha$-amylases, while high concentrations of EDTA inhibit $\alpha$-amylase activity significantly [21, 25, 27]. In the case of rAmySL3, calcium ion had no activating effect on rAmySL3 activity, but was inhibitory at high concentrations (Fig. 5A). In addition, EDTA-treated rAmySL3 remained highly active and showed $\mathrm{Ca}^{2+}$-independence (Fig. 5B). Usually, EDTA greatly inhibits the activity of $\mathrm{Ca}^{2+}$-dependent $\alpha$-amylases but has no or minor effect on the $\mathrm{Ca}^{2+}$ independent $\alpha$-amylases. Although rAmySL3 did not require $\mathrm{Ca}^{2+}$ for catalysis, its activity was inhibited by EDTA (Fig. 5C). Another study has reported that some $\alpha$-amylases do not require $\mathrm{Ca}^{2+}$ for activity but are inhibited by EDTA [31]. One possible explanation is that EDTA itself might be an inhibitor of the $\alpha$-amylase, rather than inhibiting the enzyme by chelating the metal ions.

Halophilic $\alpha$-amylases might be highly tolerant to organic solvents because they function under low water conditions [32]. rAmySL3 remained highly active in the presence of hydrophobic solvents, while it lost activity in hydrophilic solvents (Table 3). Polar solvents may strip off essential water molecules from the active site of the enzyme and result in enzyme inactivation. The same phenomenon has 
been found in the organic solvent-tolerant $\alpha$-amylases from halophilic Archaea Haloarcula sp. strain S-1 [24] and Haloterrigena turkmenica [33]. Although rAmySL3 was inhibited by anionic surfactant SDS, it was more tolerant to nonionic surfactants (Tween-20, Tween-80, and Triton X$100)$ at higher concentrations than other reported halophilic $\alpha$-amylases [33-36].

High content of acidic amino acid is usually found in halophilic proteins. Acidic amino acids on the surface facilitate the binding and maintenance of essential water molecules, making the proteins soluble, stable, and functional under high salinity conditions [32, 37]. rAmySL3 contains $20.7 \%$ acidic amino acids, which is lower than that of $\alpha$-amylase from Natronococcus sp. Ah-36 [38], but higher than those of other halophilic or halotolerant counterparts (Table 2). In addition, most of the acidic amino acids display on the enzyme surface, which accounts for a negative electrostatic potential (Fig. 2). Moreover, rAmySL3 has a hydrophobic amino acid content of $30.0 \%$, which is higher than that of $\alpha$-amylase AmyZ from Z. profunda [27], but lower than those of other nine halophilic or halotolerant $\alpha$-amylases (Table 2). These factors might allow rAmySL3 to form a solvation shell that keeps the protein surface hydrated and thus highly active and tolerant to high concentrations of salt.

In this study, a new $\alpha$-amylase gene (amySL3) was cloned from a halophilic isolate Alkalibacterium sp. SL3 and expressed in E. coli. Biochemical characterizations demonstrated that rAmySL3 is an extremely halophilic, low-temperatureactive, calcium-independent $\alpha$-amylase with great tolerance to surfactants and organic solvents. These enzymatic properties give rAmySL3 broad potential for various applications, such as hypersaline waste treatment, processing seafood and saline food, and so on. Moreover, the polyextremophilic rAmySL3 represents a good candidate for basic research into the structure-function relationship.

\section{Acknowledgments}

This work was supported by the National Natural Science Foundation of China (31301406), the Marine Biological Enzyme Engineering Platform for Innovative Services (2014FJPT02), and the China Scholarship Council (20173059).

\section{Conflict of Interest}

The authors have no financial conflicts of interest to declare.

\section{References}

1. Guzman-Maldonado H, Paredes-Lopez O. 1995. Amylolytic enzymes and products derived from starch: a review. Crit. Rev. Food Sci. Nutr. 35: 373-403.

2. van der Maarel MJ, van der Veen B, Uitdehaag JC, Leemhuis H, Dijkhuizen L. 2002. Properties and applications of starch-converting enzymes of the alpha-amylase family. J. Biotechnol. 94: 137-155.

3. MacGregor EA. 1988. Alpha-amylase structure and activity. J. Protein Chem. 7: 399-415.

4. Janecek S, Svensson B, MacGregor EA. 2014. AlphaAmylase: an enzyme specificity found in various families of glycoside hydrolases. Cell Mol. Life Sci. 71: 1149-1170.

5. Mikawlrawng K. 2016. Aspergillus in biomedical research, pp. 229-242. In Gupta VK (ed.), New and Future Developments in Microbial Biotechnology and Bioengineering, Elsevier, Amsterdam.

6. Pandey A, Nigam P, Soccol CR, Soccol VT, Singh D, Mohan R. 2000. Advances in microbial amylases. Biotechnol. Appl. Biochem. 31 (Pt 2): 135-152.

7. de Souza PM, de Oliveira Magalhaes P. 2010. Application of microbial alpha-amylase in industry - A review. Braz. J. Microbiol. 41: 850-861.

8. Zhang Q, Han Y, Xiao H. 2017. Microbial alpha-amylase: A biomolecular overview. Process Biochem. 53: 88-101.

9. Kambourova M. 2017. Recent advances in extremophilic alpha-amylases, pp. 99-113. In Sani RK, Krishnaraj RN (eds.), Extremophilic Enzymatic Processing of Lignocellulosic Feedstocks to Bioenergy, Springer International Publishing, Cham.

10. van den Burg B. 2003. Extremophiles as a source for novel enzymes. Curr. Opin. Microbiol. 6: 213-218.

11. Cipolla A, Delbrassine F, Da Lage JL, Feller G. 2012. Temperature adaptations in psychrophilic, mesophilic and thermophilic chloride-dependent alpha-amylases. Biochimie 94: 1943-1950.

12. D'Amico S, Marx JC, Gerday C, Feller G. 2003. Activitystability relationships in extremophilic enzymes. J. Biol. Chem. 278: 7891-7896.

13. Kumar S, Grewal J, Sadaf A, Hemamalini R, Khare SK. 2016 Halophiles as a source of polyextremophilic alpha-amylase for industrial applications. AIMS Microbiol. 2: 1-26

14. Wang G, Wang Q, Lin X, Ng TB, Yan R, Lin J, et al. 2016. A novel cold-adapted and highly salt-tolerant esterase from Alkalibacterium sp. SL3 from the sediment of a soda lake. Sci. Rep. 6: 19494.

15. Wang G, Wu J, Yan R, Lin J, Ye X. 2016. A novel multidomain high molecular, salt-stable alkaline xylanase from Alkalibacterium sp. SL3. Front. Microbiol. 7: 2120.

16. Yang J, Yan R, Roy A, Xu D, Poisson J, Zhang Y. 2015. The I-TASSER Suite: protein structure and function prediction. Nat. Methods 12: 7-8. 
17. Suvd D, Fujimoto Z, Takase K, Matsumura M, Mizuno H. 2001. Crystal structure of Bacillus stearothermophilus alphaamylase: possible factors determining the thermostability. J. Biochem. 129: 461-468.

18. Wu S, Zhang Y. 2008. MUSTER: Improving protein sequence profile-profile alignments by using multiple sources of structure information. Proteins 72: 547-556.

19. Miller GL. 1959. Use of dinitrosalicylic acid reagent for determination of reducing sugar. Anal. Chem. 31: 426-428.

20. Alikhajeh J, Khajeh K, Ranjbar B, Naderi-Manesh H, Lin YH, Liu E, et al. 2010. Structure of Bacillus amyloliquefaciens alpha-amylase at high resolution: implications for thermal stability. Acta Crystallogr. Sect. F Struct. Biol. Cryst. Commun. 66: 121-129.

21. Yamaguchi R, Tokunaga $H$, Ishibashi $M$, Arakawa $T$, Tokunaga M. 2011. Salt-dependent thermo-reversible alphaamylase: cloning and characterization of halophilic alphaamylase from moderately halophilic bacterium, Kocuria varians. Appl. Microbiol. Biotechnol. 89: 673-684.

22. Antony CP, Kumaresan D, Hunger S, Drake HL, Murrell JC, Shouche YS. 2013. Microbiology of Lonar Lake and other soda lakes. ISME J. 7: 468-476.

23. Ji S, Jian-ting C, Yan-hong W, Matsumoto R, Qing-yi S. 2001. Paleoclimatic changes in Dabusu Lake. Chin. J. Oceanol. Limnol. 19: 91-96.

24. Fukushima T, Mizuki T, Echigo A, Inoue A, Usami R. 2005. Organic solvent tolerance of halophilic alpha-amylase from a Haloarchaeon, Haloarcula sp. strain S-1. Extremophiles 9: 85-89.

25. Hutcheon GW, Vasisht N, Bolhuis A. 2005. Characterisation of a highly stable alpha-amylase from the halophilic archaeon Haloarcula hispanica. Extremophiles 9: 487-495.

26. Moshfegh M, Shahverdi AR, Zarrini G, Faramarzi MA. 2013. Biochemical characterization of an extracellular polyextremophilic alpha-amylase from the halophilic archaeon Halorubrum xinjiangense. Extremophiles 17: 677-687.

27. Qin Y, Huang Z, Liu Z. 2014. A novel cold-active and salttolerant alpha-amylase from marine bacterium Zunongwangia profunda: molecular cloning, heterologous expression and biochemical characterization. Extremophiles 18: 271-281.

28. Srimathi S, Jayaraman G, Feller G, Danielsson B, Narayanan PR. 2007. Intrinsic halotolerance of the psychrophilic alphaamylase from Pseudoalteromonas haloplanktis. Extremophiles 11: 505-515.

29. Wang X, Kan G, Ren X, Yu G, Shi C, Xie Q, et al. 2018. Molecular cloning and characterization of a novel alphaamylase from Antarctic sea ice bacterium Pseudoalteromonas sp. M175 and its primary application in detergent. Biomed. Res. Int. 2018: 3258383.

30. Feller G. 2013. Psychrophilic enzymes: from folding to function and biotechnology. Scientifica 2013: 512840.

31. Li Z, Wu J, Zhang B, Wang F, Ye X, Huang Y, et al. 2015. AmyM, a novel maltohexaose-forming alpha-amylase from
Corallococcus sp. strain EGB. Appl. Environ. Microbiol. 81: 1977-1987.

32. Karan R, Capes MD, Dassarma S. 2012. Function and biotechnology of extremophilic enzymes in low water activity. Aquat. Biosyst. 8: 4.

33. Santorelli M, Maurelli L, Pocsfalvi G, Fiume I, Squillaci G, La Cara F, et al. 2016. Isolation and characterisation of a novel alpha-amylase from the extreme haloarchaeon Haloterrigena turkmenica. Int. J. Biol. Macromol. 92: 174-184.

34. Kiran KK, Chandra TS. 2008. Production of surfactant and detergent-stable, halophilic, and alkalitolerant alpha-amylase by a moderately halophilic Bacillus sp. strain TSCVKK. Appl. Microbiol. Biotechnol. 77: 1023-1031.

35. Shafiei M, Ziaee A-A, Amoozegar MA. 2010. Purification and biochemical characterization of a novel SDS and surfactant stable, raw starch digesting, and halophilic $\alpha$-amylase from a moderately halophilic bacterium, Nesterenkonia sp. strain F. Process Biochem. 45: 694-699.

36. Shafiei M, Ziaee AA, Amoozegar MA. 2011. Purification and characterization of an organic-solvent-tolerant halophilic alpha-amylase from the moderately halophilic Nesterenkonia sp. strain F. J. Ind. Microbiol. Biotechnol. 38: 275-281.

37. Sinha R, Khare SK. 2014. Protective role of salt in catalysis and maintaining structure of halophilic proteins against denaturation. Front. Microbiol. 5: 165.

38. Kobayashi T, Kanai H, Aono R, Horikoshi K, Kudo T. 1994. Cloning, expression, and nucleotide sequence of the alphaamylase gene from the haloalkaliphilic archaeon Natronococcus sp. strain Ah-36. J. Bacteriol. 176: 5131-5134.

39. Onodera M, Yatsunami R, Tsukimura W, Fukui T, Nakasone K, Takashina T, et al. 2013. Gene analysis, expression, and characterization of an intracellular alphaamylase from the extremely halophilic archaeon Haloarcula japonica. Biosci. Biotechnol. Biochem. 77: 281-288.

40. Wei Y, Wang X, Liang J, Li X, Du L, Huang R. 2013. Identification of a halophilic alpha-amylase gene from Escherichia coli JM109 and characterization of the recombinant enzyme. Biotechnol. Lett. 35: 1061-1065.

41. Coronado MJ, Vargas C, Mellado E, Tegos G, Drainas C, Nieto JJ, et al. 2000. The alpha-amylase gene amyH of the moderate halophile Halomonas meridiana: cloning and molecular characterization. Microbiology 146 (Pt 4): 861-868.

42. Mijts BN, Patel BK. 2002. Cloning, sequencing and expression of an alpha-amylase gene, amyA, from the thermophilic halophile Halothermothrix orenii and purification and biochemical characterization of the recombinant enzyme. Microbiology 148: 2343-2349.

43. Feller G, Lonhienne T, Deroanne C, Libioulle C, van Beeumen J, Gerday C. 1992. Purification, characterization, and nucleotide sequence of the thermolabile alpha-amylase from the antarctic psychrotroph Alteromonas haloplanctis A23. J. Biol. Chem. 267: 5217-5221. 